\title{
Assessing Nursing Students' Attitude Toward Nursing Process Software
}

\section{Kobra Parvan}

Tabriz University of Medical Sciences

Fahimeh Alsadat Hosseini ( $\sim$ fhoseini221@gmail.com )

Shiraz University of Medical Sciences https://orcid.org/0000-0001-5943-9294

Madineh Jasemi

Urmia University of Medical Sciences

Brian Thomson

University of the West of Scotland

Samaneh Bagherian

Birjand University of Medical Sciences

\section{Research article}

Keywords: Attitude, Nursing student, Software, Nursing process

Posted Date: July 7th, 2020

Dol: https://doi.org/10.21203/rs.3.rs-38284/v1

License: (c) (i) This work is licensed under a Creative Commons Attribution 4.0 International License. Read Full License 


\section{Abstract}

Background: The nursing process is the core and the standard of practice in nursing profession. Nowadays, the use of information technology in the field of nursing processes, education and practice has been emphasized. Since nurse's attitudes towards clinical information systems are considered as an indicator of the success rate of information systems, and nurse's attitudes about the nursing process can effect their execution of the process. So the purpose of this study was to evaluate nursing students' attitudes in the field of the nursing process software.

Methods: In this quasi-experimental study, 160 undergraduate nursing students (terms 4-8) in Tabriz University of Medical Sciences were selected by convenience sampling. To evaluate the effectiveness of nursing process software in this study, Mazlom and rajabpoor (2014) questionnaire consisted of 21 components based on a five-point Likert scale was completed by students after using the software. Data were then analyzed by SPSS 19 software.

Results: The mean score of students' attitude toward nursing process software was good $(80.70 \pm 5.58)$. The highest student satisfaction with the software was respectively in the fields of "Effectiveness of software in prioritizing patient care and problems", "Completeness of electronic patient information compared to handwritten mode" and "Software effectiveness in saving your time". Also, the lowest level of students' satisfaction with the software was respectively related to the "sense of fairness in the work-division based on the software", "the effectiveness of the software in determining your workload" and "the sense of satisfaction in the work-division based on the software". There was a statistically significant relationship between gender and age and students' attitude toward nursing process software.

Conclusions: Nursing students had a positive attitude about nursing process software. Therefore, in order to make the most use of the nursing process it is recommended to use this software in educational, research and clinical fields, which require a substructure of the nursing process software in universities and clinics.

\section{Background}

The nursing process is a systematic and dynamic method of patient care [1]. The nursing process is the core [2] and the standard of practice in nursing profession [3]. Lydia Hall is the first person to introduce the concept of the nursing process in nursing in 1955. Nursing process theory has been widely accepted by nurses since $1967[4,5]$.

The use of the nursing process has contributed to the delivery and planning of desirable, clear and effective nursing care, and is ultimately effective in improving the quality of patient care [6]. Using the nursing process in the clinic has many benefits for the patient (reducing period of hospitalization, receiving qualified care), nurse (increasing job satisfaction, decreasing irrational and unscientific obedience to the physician), and for the nursing profession (contributing to nursing development and independence). In other words, if nursing practice proceeds according to the steps of the nursing process, patients receive appropriate care in the least time with maximum competence $[7,8]$.

Based on some studies, nursing process faces many challenges in practice [9]. A systematic approach to teaching and implementing the nursing process is rarely followed in hospitals [2]. Mamseri (2012) found in his study that $81 \%$ of nurses are trained in the nursing process, but only $43 \%$ are able to perform it [10] and according to the results of one study only $13.3 \%$ of nurses use nursing process in their nursing care incompletely [11]. Evidence shows that not only is the nursing process incompletely performed by nurses working in hospitals, but also by nursing students and teachers [12-14]. Based on some studies, there have been problems in establishing and using the nursing process in many institutions during the last year, especially in developed countries [15]. In the United States, all nursing students are trained using the nursing process in the first year of entering the nursing field [16]. In addition, the results of Akbari`s study (2011) showed that nursing instructors working in Tehran Higher Education Centers were not completely aware of the concept of the nursing process and its application in the clinic and most of them have only moderate knowledge of the nursing process which is not completely integrated into clinical practice even by the teachers themselves [12].

Not to apply the nursing process as a standard of care causes problems such as decreased job satisfaction, decreased scientific nursing practice, thoughtless obedience, reduced quality of care delivery and over dependence on physicians [13].

Factors affecting the implementation of the nursing process are varied and complex [17]. One of the barriers to the implementation of the nursing process is the low value attitude of nurses towards the nursing process [3]. Nurses who have a positive knowledge and attitude towards the nursing process are more interested in using it [18]. In a qualitative study by Atashzadeh Shoorideh and Ashktorab (2011), looking at factors influencing the use of the nursing process by nurses concluded that knowledge, skills, and attitudes toward the nursing process influence its implementation [3]. According to some experts, the nursing process in the current context is unclear, time consuming and difficult to implement $[19,20]$.

Therefore, it seems necessary to use other methods to improve nursing students' attitudes towards the nursing process and persuade them to practice this process in clinical settings in the future [13]. In this regard, it should be noted that $92 \%$ of nursing students mostly prefer new and active learning methods than traditional and inactive ones [21]. Nursing instructors should develop new learning methods to prevent nursing students from superficial learning and develop their critical thinking skills, problem solving and also their knowledge and information retention [22]. Improving and developing different learning methods and integrating models are important activities that have been addressed in recent years [23]. In this regard, e-learning is considered as a type of individual education in which learners are able to achieve educational goals according to their talents [24]. Information technology is used to improve clinical documentation and supports the development of computerized nursing process software. This would help to integrate a logical structure of data, information and knowledge when making nursing care decisions [25]. Professionals should use these technologies and integrate computer science, information and nursing to expand functional tools, education and research and thus enhance the nursing process [26]. Advances in nursing informatics are also aimed to increase the time available for professionals to perform humanitarian and care activities [27]. Many methods have been used to evaluate the consequences of Loading [MathJax]/jax/output/CommonHTML/jax.js 
implementing information systems [28]. Among these methods, surveying information systems users' attitudes is still considered as an effective and efficient way of obtaining feedback from nurses about the effectiveness of information systems [29]. Studies have shown that nurses attitudes and satisfaction with clinical information systems are considered as an indicator of the success rate of information systems [30-32] and nurses' attitudes towards the nursing process can effect the implementation of the process [33]. However, considering the undeniable benefits of the nursing process [34] and the lack of its application in clinical care [12] together with the influence of nursing professionals' attitude on using nursing process [18], and finally the importance of using information technology on Nursing Process teaching and practice [25]. The purpose of this study was to evaluate attitudes of nursing students towards using nursing process software.

\section{Methods}

This study is a quasi-experimental study that was done to determine the attitudes of nursing students regarding the nursing process software. We used the nursing students of Tabriz University of Medical Sciences in 2018. The study population consisted of all undergraduate nursing students in terms 4-8. The total number in our sample was 160 people selected by the convenience sampling method. Criteria for participation in the study included; willingness to participate in all stages of study, undergraduate terms 4-8 students at Tabriz University of Medical Sciences, basic knowledge of computer use, and two weeks of continuous use of the nursing process software (with a minimum of 4 patients).

In this study, a two-part questionnaire was used. The first part consisted of socio-demographic characteristics of the participants and consisted of 11 questions. And the second part was Mazlom and rajabpoors(2014) questio $\cap$ airewhichassessed $\nu$ rsingstudents attitudes towards nursing process software [35]. This questionnaire consisted of 21 items based on a five-point Likert scale (1: very low, 2: low, 3: average, 4: good, and 5: very good). The validity and reliability of the primary instruments in the study by Mazlom and rajabpoor (2014) were investigated in Iran. The content validity of the questionnaire was confirmed by 10 experts and the reliability of the tool was assessed by retesting method (0.81) [35]. The questionnaire's score is calculated based on the sum of the total scores.

After obtaining consent to conduct research from the University Research Council and ethical permit from the relevant field, (IR. TBZMED.REC.1393.214), firstly some information about the research and assurance regarding the confidentiality of the information obtained, and the privacy and of the participants was provided. Participants were also assured that participation was optional. After containing written consent from participants and explaining goals of the study, undergraduate nursing students from terms 4-8 of Tabriz University of Medical Sciences who were undergoing internship in medical surgical wards were selected using random sampling. To design the nursing process software, extensive text review and also the latest international standards relating to the American nursing association, NANDA were consulted. In addition, nursing diagnosis list (2018-2020) and also reference care books in Nursing such as Ulrich and .... were used. The software consisted of six steps of 1. Assessment 2. Nursing diagnosis 3. Determining goals and expected outcomes 4 . Planning 5. Implementation and 6. Evaluation. The software was designed in CD and web-based forms. This way, students could use this software through their cell phones using their network connection. Nursing students were able to access the different steps of the nursing process by simply entering the patient's characteristics and information related to the surveys carried out. Initially, students were taught how to use the designed software. Nursing process software was provided to students for two weeks of working with patients. Then the attitude-test questionnaire about nursing process software was completed by students using self-report method. The data were collected from May to June of 2019.

After data collection, data were analyzed by SPSS (Statistical Package for Social Sciences) software version 19 using descriptive statistics test (mean and standard deviation) and analytical statistics (independent t-test and one-way ANOVA).

\section{Results}

In the present study, the total number of participants was 160 people. The mean age of the participants was $23.02 \pm 3.13$. Also the mean score of students was $16.1 \pm 36.18$. Nursing interest based on the 10-point scale in the experimental group was $5.19 \pm 1.65$. Other socio-demographic characteristics of the students participating in the study are presented in Table 1. 
Table 1

Socio-demographic characteristics of the participants

\begin{tabular}{|c|c|c|}
\hline \multicolumn{2}{|l|}{ Socio-demographic characteristics } & \multirow{2}{*}{$\begin{array}{l}\text { Frequency (\%) } \\
96(60)\end{array}$} \\
\hline $\operatorname{Sex} F(\%)^{\star \star}$ & Female & \\
\hline & Male & $64(40)$ \\
\hline \multirow[t]{2}{*}{ Marital status F (\%) } & Single & $115(71.9)$ \\
\hline & married & $45(28.1)$ \\
\hline \multirow[t]{5}{*}{ Semester F (\%) } & Four & $27(16.9)$ \\
\hline & Five & $39(24.4)$ \\
\hline & Six & $41(25.6)$ \\
\hline & Seven & $24(15)$ \\
\hline & Eight & $29(18.1)$ \\
\hline \multirow[t]{2}{*}{ Acquaintance with computer or related software use $F(\%)$} & Yes & $153(95.6)$ \\
\hline & No & $7(4.4)$ \\
\hline \multirow[t]{5}{*}{ Attitude toward computer use in nursing affairs } & Completely agree & $46(28.8)$ \\
\hline & Agree & $68(42.5)$ \\
\hline & No ideas & $27(16.9)$ \\
\hline & Disagree & $19(11.9)$ \\
\hline & Completely disagree & $0(0)$ \\
\hline \multirow[t]{4}{*}{ Nationality F (\%) } & Turk & $26(16.3)$ \\
\hline & Fars & $84(52.2)$ \\
\hline & Kurd & 19 (11.9) \\
\hline & Lor & $31(19.4)$ \\
\hline \multirow[t]{2}{*}{ Student work record $\mathrm{F}(\%)$} & Yes & $63(39.4)$ \\
\hline & No & $97(60.6)$ \\
\hline
\end{tabular}

Table 2 presents the mean scores of nursing students based on the Likert scale and frequency (percentage) in each item of assessing students' attitude to the nursing process software's questionnaire. The highest students' satisfaction with the software was respectively related to "Effectiveness of software in prioritizing patient care and problems", "Completeness of patient's electronic information compared to handwritten mode" and "Software's effectiveness in saving your time". Also, the lowest level of students' satisfaction with the software was respectively related to the "feeling of fairness in labor division based on the software", "the effectiveness of the software in determining your workload" and "the feeling of satisfaction in labor division based on the software".

The mean score of students' attitude toward nursing process software was $80.70 \pm 5.58$. Based on the three-part score range, scores of lower one-third were identified (poor) 21-49, middle one-third (medium) 50-77, and higher one-third (desirable) 78-105, so students` attitude scores were considered desirable. 
Table 2

Frequency distribution (percentage) of nursing students' attitudes toward the nursing process software and mean and standard deviation of questionnaire's items based on Likert scale.

\begin{tabular}{|c|c|c|c|c|c|c|}
\hline Item & $\begin{array}{l}\text { Very } \\
\text { low } \\
\text { F (\%)* }\end{array}$ & $\begin{array}{l}\text { Low } \\
F(\%)\end{array}$ & $\begin{array}{l}\text { Average } \\
F(\%)\end{array}$ & $\begin{array}{l}\text { Good } \\
F(\%)\end{array}$ & $\begin{array}{l}\text { Very good F } \\
\text { (\%) }\end{array}$ & $\underset{S D^{* \star}}{\operatorname{Mean} \pm}$ \\
\hline Simplicity of software use & $1(0.6)$ & $1(0.6)$ & $\begin{array}{l}38 \\
(23.8)\end{array}$ & $\begin{array}{l}75 \\
(46.9)\end{array}$ & $45(28.1)$ & $4.01 \pm 0.78$ \\
\hline Software installing & $8(5)$ & $\begin{array}{l}22 \\
(13.8)\end{array}$ & $\begin{array}{l}37 \\
(23.1)\end{array}$ & $72(45)$ & $21(13.1)$ & $3.48 \pm 1.05$ \\
\hline Simplicity and beauty of software environment & $1(0.6)$ & $8(5)$ & $\begin{array}{l}52 \\
(32.5)\end{array}$ & $\begin{array}{l}67 \\
(41.9)\end{array}$ & $32(20)$ & $3.76 \pm 0.85$ \\
\hline Suitable software execution speed & - & $9(5.6)$ & $\begin{array}{l}60 \\
(37.5)\end{array}$ & $\begin{array}{l}67 \\
(41.9)\end{array}$ & $24(15)$ & $3.66 \pm 0.8$ \\
\hline \multirow[t]{2}{*}{ Printable cares and diagnosis } & - & & & & $28(17.5)$ & $3.67 \pm 0.89$ \\
\hline & & $\begin{array}{l}17 \\
(10.6)\end{array}$ & $\begin{array}{l}47 \\
(29.4)\end{array}$ & $\begin{array}{l}68 \\
(42.5)\end{array}$ & & \\
\hline Effectiveness of software in quality of care improvement & - & $14(8.8)$ & $\begin{array}{l}53 \\
(33.1)\end{array}$ & $\begin{array}{l}50 \\
(31.3)\end{array}$ & $43(26.9)$ & $3.76 \pm 0.99$ \\
\hline Effectiveness of software in increasing patient's quality of care & - & $2(1.3)$ & $40(25)$ & $\begin{array}{l}67 \\
(41.9)\end{array}$ & $51(31.9)$ & $4.04 \pm 0.79$ \\
\hline Effectiveness of software in increasing quality of care cohesion & - & $3(1.9)$ & $\begin{array}{l}22 \\
(13.8)\end{array}$ & $\begin{array}{l}67 \\
(41.9)\end{array}$ & $68(42.5)$ & $4.25 \pm 0.76$ \\
\hline Effectiveness of software in saving your time & - & $3(1.9)$ & $13(8.1)$ & $\begin{array}{l}65 \\
(40.6)\end{array}$ & $79(49.4)$ & $4.37 \pm 0.72$ \\
\hline $\begin{array}{l}\text { Patient's electronic information's' preciseness compared to handwritten } \\
\text { mode }\end{array}$ & - & $1(0.6)$ & $\begin{array}{l}33 \\
(20.6)\end{array}$ & $\begin{array}{l}62 \\
(38.8)\end{array}$ & $64(40)$ & $4.18 \pm 0.78$ \\
\hline Accuracy of electronic information compared to handwritten mode & - & - & $24(15)$ & $\begin{array}{l}60 \\
(37.5)\end{array}$ & $76(47.5)$ & $4.33 \pm 0.72$ \\
\hline $\begin{array}{l}\text { Completeness of patient's electronic information compared to handwritten } \\
\text { mode }\end{array}$ & - & $2(1.3)$ & $16(10)$ & $56(35)$ & $86(53.8)$ & $4.41 \pm 0.72$ \\
\hline Effectiveness of software in increasing your level of knowledge & $4(2.5)$ & $1(0.6)$ & $48(30)$ & $\begin{array}{l}69 \\
(43.1)\end{array}$ & $38(23.8)$ & $3.85 \pm 0.88$ \\
\hline Effectiveness of software in determining your workload & $9(5.6)$ & $\begin{array}{l}29 \\
(18.1)\end{array}$ & $\begin{array}{l}68 \\
(42.5)\end{array}$ & $\begin{array}{l}39 \\
(24.4)\end{array}$ & $15(9.4)$ & $3.14 \pm 1$ \\
\hline Feeling of fairness in work division based on software & $\begin{array}{l}10 \\
(6.3)\end{array}$ & $\begin{array}{l}30 \\
(18.8)\end{array}$ & $\begin{array}{l}77 \\
(48.1)\end{array}$ & $\begin{array}{l}43 \\
(26.9)\end{array}$ & - & $2.96 \pm 0.84$ \\
\hline Feeling of satisfaction in work division based on software & $5(3.1)$ & $\begin{array}{l}26 \\
(16.3)\end{array}$ & $\begin{array}{l}68 \\
(42.5)\end{array}$ & $48(30)$ & $13(8.1)$ & $3.24 \pm 0.93$ \\
\hline $\begin{array}{l}\text { Effectiveness of software in identifying alarm signs and doing effective } \\
\text { reaction }\end{array}$ & - & $\begin{array}{l}17 \\
(10.6)\end{array}$ & $\begin{array}{l}51 \\
(31.9)\end{array}$ & $72(45)$ & 2. (12.5) & $3.59 \pm 0.84$ \\
\hline Effectiveness of software in organizing patient's problems & - & - & $\begin{array}{l}31 \\
(19.4)\end{array}$ & $64(40)$ & $65(40.6)$ & $4.21 \pm 0.75$ \\
\hline Effectiveness of software in prioritizing patient care and problems & - & - & $10(6.3)$ & $\begin{array}{l}69 \\
(43.1)\end{array}$ & $81(50.6)$ & $4.44 \pm 0.61$ \\
\hline Effectiveness of software in preventing fault and mistake show by you & - & $32(20)$ & $\begin{array}{l}57 \\
(36.6)\end{array}$ & $\begin{array}{l}52 \\
(32.5)\end{array}$ & $19(11.9)$ & $3.36 \pm 0.93$ \\
\hline Effectiveness of software in your proper and correct decision making & - & $8(5)$ & $\begin{array}{l}30 \\
(18.8)\end{array}$ & $\begin{array}{l}79 \\
(49.4)\end{array}$ & $43(26.9)$ & $3.98 \pm 0.81$ \\
\hline \multicolumn{7}{|l|}{ *: Mean \pm Standard deviation } \\
\hline **: Frequency (Percent) & & & & & & \\
\hline
\end{tabular}

When examining the relationship between demographic characteristics and the mean scores of students

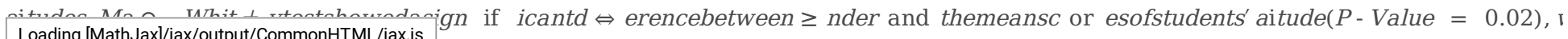
Loading [MathJax]/jax/output/CommonHTML/jax.js 
attitude scores were significantly higher. There was no significant relationship between other demographic variables and students' mean attitude scores ( $p$ > 0.05).

\section{Discussion:}

The purpose of this study was to determine the attitudes of nursing students towards the nursing process software. The mean score of students' attitudes toward the nursing process software was $80.70 \pm 5.58$. Based on the three-part range, scores of lower one-third were poor (21-49), middle one-third were medium (50-77), and higher one-third were desirable (78-105), so students` attitude scores were considered desirable.

According to the study by Liaskos and Mantas (2004), nurses in most areas had a positive attitude about using software to execute the nursing process and found them to be creative, interesting, useful and easy to use [36] which is similar to the results of this study. Based on the study of Mazlom and rajabpoor (2014), 81.3\% of the participants rated the software as good or very good. Efficiency of software in patient care was very high, so that the mean score of students' opinions was $84.3 \pm 5.83$ and for nurses was $73.2 \pm 1.13$ from total score of 100 and the use of the nursing process software was cited as a facilitator of clinical practice [35].

According to some studies, students were satisfied with the use of nursing process software in clinical practice and its efficiency in promoting clinical care [13, 35]. According to the students' attitudes in the study by Sayadi and Rokhafroz (2013), their knowledge and skills about the nursing process improved after using the software, and $86 \%$ of the students said their satisfaction from using software was high or very high [13].

However, the results of a descriptive study in Year 2008 showed that less than half of the nurses were relatively satisfied with the impact of a computerized hospital information system on patient care activities [37]. The results of the study by BabaMohamadi et al (2013) showed that more than half of the nurses did not understand the benefits of the impact of the nursing computer program on the patient care process and from their point of view the computer program influenced a limited number of patient care processes. According to the findings of this study, computer programs prevalent in the clinical nursing environment didn thavecomp $\leq$ te $\cap$ ability $\because$ theycodnt process information in all or most aspects of care [28]. In many studies, the nursing process has been defined

as a separate pathway that does not cover all stages and the most unconsidered stage was the evaluation stage $[5,25,26]$. Though the nursing process has been divided into parts, they do not occur in isolation but are interdependent and recurring [38, 39]. Also in spite of the different benefits of computer programs, traditionally some nurses have regarded information technology as an attack on routine patterns and practices and sometimes as a deviation from direct patient care [40,41]. And also some nurses may see this process of change as a challenge [42]. Based on recent text reviews, limited studies use computer systems in helping and managing aspects in the nursing process [43].

According to Amini et al. study (2017), lack of knowledge and attitude are the main barriers to the proper implementation of the nursing process, and nurses $(49.7 \%)$ who are more familiar with the nursing process and use it in care giving have a more positive attitude (62.9\%) to the nursing process [44]. In this regard, nursing education is a major part of improving the use of the nursing process and thus promoting the overall quality of nursing care [45]. The use of computer-based techniques and technologies at the bachelor level helps to make teaching more interactive and creative [46]. The use of technology and computer systems to gather, store, process and modify nursing-related data can facilitate the delivery of nursing services, enable nursing care, and support educational resources for educating nurses [47]. However, the lack of proper and correct training during college, short and inadequate training time, lack of retraining, lack of tools [48] and lack of some equipment such as computers [25] to facilitate and process implementation are sited among barriers to proper implementation of the nursing process. Other factors that may influence nurses' attitudes toward computer software include the existence of a minimum set of nursing data and standard nursing terms in computer software [28]. Also in the current health care setting with the aim of cost control, many nursing wards have insufficient staff and have little time to train and adopt new technology, which can effect their attitudes [28]. Therefore, nursing managers and nursing education authorities should try to remove existing barriers and provide the appropriate facilities to enhance the implementation of the computerized nursing process and enhance the provision of qualified services based on the nursing process.

In this study, the students' most satisfaction with the software was in the fields of "Effectiveness of software in prioritizing care and patient's problems "," Completeness of electronic patient information compared to handwritten mode" and "Software's effectiveness in saving your time". Also, the lowest level of students' satisfaction with the software was related to the "sense of fairness in the division of labor based on the software", "the effectiveness of the software in determining your workload" and "the feeling of satisfaction in the division of labor based on the software".

Consistent with the findings of the current study and based on the study of Mazlom and rajabpoor (2014), the most important benefits of software from $90 \%$ of nurses' attitudes were being effective in prioritizing diagnoses, accuracy of electronic information compared to handwriting, and helping to organize patient's problems [35]. Also, the least frequent measure of satisfaction among $10 \%$ of nurses and students participating in the study of Mazlom and rajabpoor (2014) was related to the accuracy of electronic information compared to handwriting and the effectiveness of the software in saving time [35] which are not consistent with the findings of present study. This may be due to the different software and research community in these studies. Like the present study, Kim's study (2005) about the implementation of the Nursing Diagnostics computer program showed that this program would assist nurses in the correct nursing diagnoses for patients, and the implementation of this program would improve nurse's performance and ultimately improve quality of nursing care [49]. It seems that the Software's comprehensiveness and using NANDA International Nursing Diagnosis and up-to-date care content affect the high degree of student satisfaction with software in prioritizing care and dealing with patient problems. Use of paper tools is common to register and execute a systematic nursing process [50]. But the use of these tools has received some criticism. Large amount of notes and low quality of prepared documents were emphasized as negative aspects [33]. The existence of an electronic care record system will help expand the standardization of care [51] and will make nursing care components more visible [52]. However, based on the study by BabaMohamadi et al (2013), nurses participating in the study believed that all the information needed for patient care is not recorded in a computer program [28]. Also in Kahouei et al study (2008), most staff did not record data electronically Loading [MathJax]/jax/output/CommonHTML/jax.js paper nursing reports, the main reason for this was inadequate time and a sense of rework. Nurses believed that 
the electronic system did not reduce paper use and thus leads to overwork [37]. It has been shown that despite the need to record the nursing process, interventions and outcomes, electronic nursing records may not be completely available [53]. The reasons for this seem to be insufficient training and performance support in the field of electronic documentation as well as limited software content covering the steps of the nursing process or care practice that need special attention.

Most nurses have a positive idea on the use of the nursing process, but have little interest in using it because of it being time consuming [33]. Nurses spend a lot of time on paperwork activities while the volume of patient information in medical documentation has increased [43]. In the study of Amini et al. (2017), $82.6 \%$ strongly agree that there is not enough time to perform the nursing process using the conventional pen and paper method. In this context, nursing informatics is associated with the care and management of the work process and the search for systems overlap and minimizes the time spent on paperwork and maximizes the time spent on care [54]. Using available and designed programs for the nursing process leads to more efficient and faster planning and, it leads to clarity of the nursing process steps [33]. Using software programs is a time management strategy that facilitates and accelerates the implementation of the nursing process because software programs allow nurses to enter assessment information quickly [33].

Regarding the cases where nursing students were least satisfied with the software, it should be noted that based on a review of extensive texts, in any of the studies cases such as observing the fairness of software-based division of work, the effectiveness of the software in determining workload and nursing students' satisfaction with software based work division has not been studied. However, it seems that since the clinical education system of the students use a case study method and every student is responsible for all the care of a patient, the patients are transferred to the students considering the students' academic knowledge and ability related to their semesters. However, proper division of tasks or assignment of student workload by their clinical instructors using nursing process software has not been considered, so it is suggested that nursing instructors evaluate students correctly in terms of the amount of activities and clinical learning software data especially in the steps of diagnosis, nursing intervention and implementation.

In general, from the student's point of view, the implementation of the computerized nursing process allows improved diagnosis accuracy, systematic and complete care and documentation. Although the implementation of a computer system is expensive and requires a great deal of planning and training, such systems can significantly improve patient safety by enhancing the quality of appropriate care [55] and it seems that the nursing process software not only helps to improve communication and care performance among nurses but also leads to proper interaction and improved diagnosis, together with improved care and therapeutic performance among other members of the care team.

In this study, female students had a significantly better attitude toward the nursing process software than male students. Also, the attitude scores of the younger students were significantly higher. As in the current study, Guedes et al. (2012) showed in their study that female nurses had a more positive view of the nursing process than male students [19]. Also in two other studies, female nursing students had more positive attitude compared to male students in terms of the ability to use the nursing process in providing high quality care [56, 57]. In the study of Amini et al (2017), no significant relationship was found between students' attitude score with gender [44]. It should be noted that in all of these studies nurses or nursing student's attitudes towards nursing process software have not been addressed while their attitudes towards the nursing process have been explicitly investigated so this needs to be investigated in future studies. However, it appears that in most of the studies, including the current study, most of the study's participants were women, influenced by the traditional and feminine nature of the nursing profession. Similar to this study, based on the study of Lee et al (2008) the younger age of nurses effects higher degrees of satisfaction from nursing information systems [58]. The findings of the present study were consistent with the results of the study by Lee et al. However, the results of the study by Amini et al. (2017) showed that nurse's attitude towards the nursing process significantly increased with age [44]. Also in the study of BabaMohamadi et al. (2013), younger nurses had somewhat negative attitudes toward the impact of computerized nursing programs on patient care compared to older nurses [28]. It seems that nowadays younger students are more willing and satisfied using nursing process software than older students because of their familiarity with the world of technology and informatics and the greater attractiveness of such technologies. It is also likely that students who are more experienced in the professional and educational fields will be more aware of the challenges and disadvantages of establishing different care giving practices based on the nursing process or related software.

One of the limitations of the present study is the single-group method of conducting the present study. Therefore, further semi-experimental research should be done in this regard. Another limitation of the present study is its application on only undergraduate students in specific wards (internal and surgical), and so it is suggested that it be repeated among students from other departments, and nurses and from various wards.

\section{Conclusions:}

Nursing students had a positive attitude about nursing process software, so in order to make more use of this software in providing qualitative care to the patients, using this software in the areas of teaching, research and clinical practice of students is recommended. However, there is a need for adequate training and provision of substructure in nursing process software in universities and clinics, and due to the importance of updating the content and format of nursing process software it should be used in the design of educational programs and workshops to update the knowledge and ability of using nursing process software among nursing students as well as nurses. In addition, efforts should be made to apply the nursing process software in clinic and management at executive levels, because this way student will understand the importance of using and applying this software and will be more interested in its use.

\section{Abbreviations}

SPSS: Statistical Package for Social Sciences

Declarations

Loading [MathJax]/jax/output/CommonHTML/jax.js

Page 7/10 


\section{Ethics approval and consent to participate}

The study was approved by the Ethics Committee of Tabriz University of Medical Sciences (IR. TBZMED.REC.1393.214). Informed consents were obtained from all participants.

\section{Consent for publication}

Not applicable.

\section{Availability of data and materials}

The datasets generated and/or analysed during the current study are not publicly available due to patient confidentiality but are available from the corresponding author on reasonable request.

\section{Competing interests}

The authors declare that they have no competing interests.

\section{Funding}

This study was supported by Tabriz University of Medical Sciences.

\section{Authors' contributions}

FA.H, MJ, KP and BT were responsible for the study conception and design; FA.H and SB performed the data collection; FA.H, MJ, KP, and SB performed the data analysis; FA.H, LZ and BT were responsible for the drafting of the manuscript; FA.H, MJ, KP and BT made critical revisions to the paper for important intellectual content.

\section{Acknowledgements}

This article is the result of a research project approved by the Tabriz Medical Education Research Center. The researchers appreciate authorities of Medical Sciences University of Tabriz and public educational hospitals, students participating in this study and others who sincerely assisted us in this research.

\section{References}

1. Memarian R: Application of nursing concepts and theories (Persian). Tehran: Tarbiat Modares University Press; 2011.

2. Ghafourifard M, Haririan H, Aghajanloo A, Akbari M, Shirvani Y: Obstacles of Nursing Process Application from Perspective of the Nursing Instructor and Nursing Students in Zanjan Faculty of Nursing and Midwifery. Journal of Medical Education Development 2012, 5:69-77.

3. Atashzadeh Shoorideh F, Ashktorab T: Factors influencing implementation of nursing process by nurses: A qualitative study. Knowledge and health 2011, 6(3):16-23.

4. North American Nursing Diagnosis Association: NANDA diagnosis: definitions and classification; spiritual distress 2015-17 Philadelphia: NANDA International. In.; 2015.

5. NANDA International: Nursing Diagnoses 2015-17: Definitions and Classification: Wiley; 2014.

6. Potter PJ, Frisch N: Holistic assessment and care: presence in the process. Nursing Clinics of North America 2007, 42(2):213-228.

7. Timby BK: Fundamental nursing skills and concepts: Lippincott Williams \& Wilkins; 2009.

8. Ralph SS, Taylor CM: Sparks and Taylor's Nursing Diagnosis Pocket Guide: Wolters Kluwer Health; 2013.

9. Takahashi AA, Barros ALBLd, Michel JLM, Souza MFd: Difficulties and facilities pointed out by nurses of a university hospital when applying the nursing process. Acta Paulista de Enfermagem 2008, 21:32-38.

10. Mamseri RA: The Nursing Process as a Means of Improving Patient Care: University of South Africa; 2012.

11. Akbari M: The effect of nursing process education to nurses on quality of nursing care. Theran: branche of medicine: Islamic azad university; 2009.

12. Akbari M, Shamsi A: A survey on nursing process barriers from the nurses' view of intensive care units, vol. 4; 2011.

13. Sayadi N, Rokhafroz D: Nursing students' perspectives about a mobile software on nursing process for bedside use. Iranian Journal of Medical Education 2013, 12(12):975-981.

14. Seaback WW: Nursing Process: Concepts and Applications: Cengage Learning; 2012.

15. Pokorski S, Moraes MA, Chiarelli R, Costanzi AP, Rabelo ER: Nursing process: from literature to practice. What are we actually doing? Revista latinoamericana de enfermacem 2nก9 17(3):302-307.

Loading [MathJax]/jax/output/CommonHTML/jax.js

Page $8 / 10$ 
16. Huckabay LM: Clinical reasoned judgment and the nursing process. Nursing forum 2009, 44:72-78.

17. Adeyemo F, Adenike, Olaogun A: Factors affecting the use of nursing process in health institutions in Ogbomoso town, Oyo state., vol. 3; 2013.

18. Abebe N, Hareri H, Ayana M: The Implementation of Nursing Process and Associated Factors among Nurses Working in Debremarkos and Finoteselam Hospitals, Northwest Ethiopia, 2013, vol. 03; 2014.

19. Guedes EdS, Turrini RNT, Sousa RMCd, Baltar VT, Cruz DdALMd: Attitudes of nursing staff related to the nursing process. Revista da Escola de Enfermagem da U S P 2012, 46 130-137.

20. Varcoe C: Disparagement of the nursing process: the new dogma? Journal of advanced nursing 1996, 23(1):120-125.

21. Rahmani A, Mohajjel Aghdam A, Fathi Azar E, Abdullahzadeh F: Comparing the effects of concept mapping and integration method on nursing students' learning in nursing process course in Tabriz University of Medical Sciences. Iranian Journal of medical education 2007, 7(1):41-49.

22. Sarhangi F, Masoumi M, Ebadi A, Seyyed Mazhari M, Rahmani A: Comparing the effect of lecture-and concept mapping based learning on cognitive learning levels. Iranian Journal of Critical Care Nursing 2010, 3(1):1-2.

23. Norozi Hm, Mohsenizadeh Sm, Jafary suny H, Ebrahimzadeh S: The Effect of Teaching Uning a Blend of Collaborative and Mastery of Learning Models, on Learning of Vital Signs: An Experiment onNursing and Operation Room Students of Mashhad University of Medical Sciences. IJME 2011, 11(5):544553.

24. Thiele JE: Learning patterns of online students. Journal of Nursing Education 2003, 42(8):364-366.

25. Sousa PAFd, Sasso GTMD, Barra DCC: Contributions of the electronic health records to the safety of intensive care unit patients: an integrative review. Texto \& Contexto-Enfermagem 2012, 21(4):971-979.

26. Melo ECA, Enders BC: Building information systems for the nursing process: an integrative review. Journal of Health Informatics 2013, 5(1):23-29.

27. Palomares MLE, Marques IR: Contributions of computer systems in the implementation of nursing care systematization. Journal of Health Informatics 2010, 2(3):78-82.

28. BabaMohamadi H, Kahouie M, Bayat S, Fooladian S, Shahsavane Toghan M: Nurses' Attitude toward the Effect of Nursing Electronic Reports on Patient Care. jgbfnm 2013, 10(2):77-86.

29. Hunt EC, Sproat SB, Kitzmiller RR: The Nursing Informatics Implementation Guide: Springer New York; 2013.

30. Hubner U, Ammenwerth E, Flemming D, Schaubmayr C, Sellemann B: IT adoption of clinical information systems in Austrian and German hospitals: results of a comparative survey with a focus on nursing. BMC medical informatics and decision making 2010, 10:8.

31. Carayon P, Cartmill R, Blosky MA, Brown R, Hackenberg M, Hoonakker P, Hundt AS, Norfolk E, Wetterneck TB, Walker JM: ICU nurses' acceptance of electronic health records. Journal of the American Medical Informatics Association : JAMIA 2011, 18(6):812-819.

32. Nykanen P, Kaipio J, Kuusisto A: Evaluation of the national nursing model and four nursing documentation systems in Finland-lessons learned and directions for the future. International journal of medical informatics 2012, 81(8):507-520.

33. Zamanzadeh V, Valizadeh L, Tabrizi FJ, Behshid M, Lotfi M: Challenges associated with the implementation of the nursing process: A systematic review. Iranian journal of nursing and midwifery research 2015, 20(4):411-419.

34. Karimi H: Applying nursing process education in workshop framework. Procedia - Social and Behavioral Sciences 2011, 29:561-566.

35. Mazlom SR, rajabpoor m: Development and Assessment of Computerized Software for Nursing Process: a Step toward Promotion of Nursing Education and Care. IJME 2014, 14(4):312-322.

36. Liaskos J, Mantas J: Evaluating an ICNP Web-based nursing documentation system. Studies in health technology and informatics 2004, 107(Pt 1):386390.

37. Kahouei M, Soleimani M, Qazvi S, Alaei S: Views, Behavior and Satisfaction of the Nurses and Other Hospital Ward Personnel about the Effectiveness of Computer Systems of Hospital Information on Caring Process. Health Information Management 2008, 4(2):193-202.

38. de Enfermagem CF: Resolução COFEN n 358/2009. Sistematização da Assistência de Enfermagem e a implementação do Processo de Enfermagem em ambientes, públicos ou privados, em que ocorre o cuidado profissional de Enfermagem [Internet][citado em 2010 Jul 14] Disponível em: http://www portalcofen gov br/Site/2007/materias asp 2009.

39. Barra DCC, Sasso GTMD: Mobile bedside technology: a computerized intensive care nursing process from ICNP $1.0 \AA$. Text and Context Nursing 2010, 19(1):54.

40. Cohen S: Technology's important, but nursing's irreplaceable. Nursing management 2004, 35(12):12.

41. Bartholomew K, Curtis K: High-tech, high-touch: Why wait? Nursing management 2004, 35(9):48-54.

42. Langowski C: The times they are a changing: effects of online nursing documentation systems. Quality Management in Healthcare 2005, $14(2): 121-125$.

43. Domingos CS, Boscarol GT, Brinati LM, Dias AC, de Souza CC, de Oliveira Salgado P: The application of computerized nursing process: integrative review. Enfermería Global 2017, 16(4):637-652.

44. Mohammad Amini O, Ghiasvandi S, Hamakhezri Y: The study of the incidence of neural tube defects in hospitals of Kurdistan province in 1990. muk-sena 2017, 2(3):1-9.

45. Grace G, Karani A, Ogutu M, Gachoka H: Nurses knowledge, Perspectives and Practice of the nursing Process in Two Public Hospitals in Kenya: an Interventional Study. J Nur Healthcare 2017, 2(2):1-7.

46. Keegan D: Foundations of distance education: Routledge; 2013.

47. Sadeghi R, Yaghmayi F: Informatics applying in nursing; education, research and care. Iranian Quarterly of Education Strategies 2012, 5(3):199-206.

Loading [MathJax]/jax/output/CommonHTML/jax.js 
48. Rajabpoor M, Zarifnejad GH, Mohsenizadeh SM, Mazloum SR, Pourghaznein T, Mashmoul A, Mohammad A: Barriers to the Implementation of Nursing Process From the Viewpoint of Faculty Members, Nursing Managers, Nurses, and Nursing Students. Journal of Holistic Nursing And Midwifery 2018, 28(2):137-142.

49. Kim HS: Development and Application of a Computerized Nursing Process Program for Orthopedic Surgery Inpatients: NANDA, NOC, and NIC Linkages. Journal of Korean Academy of Nursing 2005, 35(6):979-990.

50. Jafari A: Relationship between religious orientation(internal-external) methods to deal with stress among students. Behav Sci 2009, 1:91-114.

51. Moore R, Stonham G: Examining the impact of electronic care records on confidentiality and nursing practice. Nursing times 2010, 106(14):16-18.

52. Häyrinen K, Saranto K, Nykänen P: Definition, structure, content, use and impacts of electronic health records: a review of the research literature. International journal of medical informatics 2008, 77(5):291-304.

53. Kim YJ, Park HA: Analysis of nursing records of cardiac-surgery patients based on the nursing process and focusing on nursing outcomes. International journal of medical informatics 2005, 74(11-12):952-959.

54. dos Santos SR: Informática em enfermagem: desenvolvimento de software livre com aplicação assistencial e gerencial. Revista da Escola de Enfermagem da U S P 2010, 44(2):295-301.

55. Shihab L, Qassim A, Abd I: Nurses and computer- based nursing documentation system at hospital of basra city center International Journal of General Medicine and Pharmacy (IJGMP) 2018, 4(1):105-112.

56. Anonymous: Nursing students, nursing process and quality care. The Nursing journal of India 2007, 98(1):6-8.

57. Granero-Molina J, Fernandez-Sola C, Peredo de Gonzales MH, Aguilera-Manrique G, Mollinedo-Mallea J, Castro-Sanchez AM: Nursing process: what does it mean to nurses from Santa Cruz (Bolivia)? Rev Esc Enferm USP 2012, 46(4):973-979.

58. Lee TT, Mills ME, Bausell B, Lu MH: Two-stage evaluation of the impact of a nursing information system in Taiwan. International journal of medical informatics 2008, 77(10):698-707. 